\title{
USO DE REGULADORES DE CRESCIMENTO NO DESENVOLVIMENTO E PRODUÇÃO DE CROTALÁRIA ${ }^{1}$
}

\author{
Claudinei Kappes², Orivaldo Arf², Marcelo Valentini Arf², Douglas de Castilho Gitti², Andrews Molnar Alcalde²
}

\begin{abstract}
USE OF GROWTH REGULATORS

IN Crotalaria juncea L. GROWTH AND YIELD

Studies have pointed out the viability of the application of growth regulators in agriculture, however, information referring their use in Crotalaria juncea are still rare. Thus, this study aimed to evaluate the influence of the foliar application of growth regulators (mepiquat chloride, etil-trinexapac, and paclobutrazol), at different doses $\left(0 \mathrm{~g} \mathrm{ha}^{-1}, 75 \mathrm{~g} \mathrm{ha}^{-1}, 150 \mathrm{~g} \mathrm{ha}^{-1}, 225 \mathrm{~g} \mathrm{ha}^{-1}\right.$, and $\left.300 \mathrm{~g} \mathrm{ha}^{-1}\right)$, on the vegetative and reproductive development of Crotalaria juncea L. The experiment was carried out in 2010, in Selvíria, Mato Grosso do Sul State, Brazil. The experimental design was randomized blocks, in a $3 \times 5$ (regulators $\mathrm{x}$ doses) factorial scheme, with four replications. Agronomic traits, yield, and the $\mathrm{F}$ test results were evaluated, being the regulators averages compared by the Tukey test $(p<0.05)$ and doses compared by regression analysis. Growth regulators influenced the vegetative and reproductive development of Crotalaria juncea. The increase of etil-trinexapac and paclobutrazol doses reduced linearly the plant height, while the use of mepiquat chloride and paclobutrazol increased the number of pods and seeds per plant and reduced yield. The final plants population, number of seeds per pod, and weight of one thousand seeds were not affected by the growth regulators.
\end{abstract}

KEY-WORDS: Crotalaria juncea $\mathrm{L}_{\text {.; }} \mathrm{GA}_{3}$ inhibitor; yield.

\section{INTRODUÇÃO}

Uma alternativa para a sustentabilidade dos cultivos agrícolas pode ser a utilização de adubos verdes. Esta modalidade de adubação orgânica melhora as propriedades físicas, químicas e biológicas dos solos (Malavolta et al. 2000), mobiliza nutrientes, reduz gastos com fertilizantes minerais, protege o solo da erosão causada por chuvas e promove aumentos nos rendimentos das principais culturas, além de controlar

\section{RESUMO}

Estudos têm evidenciado a viabilidade da aplicação de reguladores de crescimento na agricultura, entretanto, informações referentes à sua utilização em crotalária ainda são escassas. Diante disto, este trabalho objetivou avaliar a influência da aplicação foliar de reguladores de crescimento (cloreto de mepiquat, etil-trinexapac e paclobutrazol), em diferentes doses $\left(0 \mathrm{~g} \mathrm{ha}^{-1}, 75 \mathrm{~g} \mathrm{ha}^{-1}, 150 \mathrm{~g} \mathrm{ha}^{-1}, 225 \mathrm{~g} \mathrm{ha}^{-1} \mathrm{e}\right.$ $300 \mathrm{~g} \mathrm{ha}^{-1}$ ), sobre o desenvolvimento vegetativo e reprodutivo de Crotalaria juncea L. O experimento foi conduzido em 2010, em Selvíria (MS). O delineamento experimental foi o de blocos ao acaso, em esquema fatorial $3 \times 5$ (reguladores $\mathrm{x}$ doses), com quatro repetições. Foram mensurados caracteres agronômicos e produtividade e os resultados submetidos ao teste $\mathrm{F}$, sendo as médias de reguladores comparadas pelo teste Tukey $(\mathrm{p}<0,05)$ e as de doses pela análise de regressão. Os reguladores de crescimento influenciaram no desenvolvimento vegetativo e reprodutivo da crotalária. O incremento nas doses de etil-trinexapac e paclobutrazol reduziu linearmente a altura de planta, ao passo que, para o cloreto de mepiquat e paclobutrazol, houve aumento no número de vagens e sementes por planta e redução de produtividade. A população final de plantas, número de sementes por vagem e massa de mil sementes não foram afetados pelos reguladores.

PALAVRAS-CHAVE: Crotalaria juncea L.; inibidores da síntese de $\mathrm{GA}_{3}$; produtividade.

nematóides e plantas daninhas. Segundo Favero et al. (2001), a adubação verde pode provocar modificações na população de plantas daninhas, devido aos efeitos alelopáticos e à competição por luz, água, oxigênio e nutrientes, acarretando a supressão de algumas delas.

Dentre as plantas utilizadas para fins de adubação verde destacam-se as leguminosas (Erasmo et al. 2004). A Crotalaria juncea L. é uma espécie de clima tropical da família das leguminosas, cujo uso, como adubo verde, é amplamente preconizado, face

1. Trabalho recebido em ago./2010 e aceito para publicação em out./2011 (nº registro: PAT 10768/ DOI: 10.5216/pat.v41i4.10768).

2. Universidade Estadual Paulista, Faculdade de Engenharia de Ilha Solteira (FEIS/Unesp), Ilha Solteira, SP, Brasil.

E-mails: kappes.agro@gmail.com,arf@agr.feis.unesp.br, marceloarf@hotmail.com, gittidouglas@hotmail.com, andrews_molnar@hotmail.com. 
ao seu rápido crescimento, grande potencial de produção de biomassa e reciclagem de nutrientes, fácil decomposição e eficiência na fixação biológica do nitrogênio atmosférico (Dourado et al. 2001, Pereira et al. 2005, Kappes 2011), proporcionando, desta forma, a incorporação de quantidades expressivas deste nutriente aos sistemas de cultivo (Guerra et al. 2004).

Pelo fato de a crotalária ser uma planta utilizada para prática da adubação verde, o agricultor não tem o hábito de cultivá-la visando à obtenção de lucratividade direta, pela comercialização de sementes, por exemplo. Mas, como opção de renda extra, pode-se cultivar a crotalária para fins de produção de sementes (Dourado et al. 2001), haja vista que, nos últimos anos, tem ocorrido maior demanda por sementes, principalmente devido à sua utilização em reformas de canaviais. Contudo, dependendo da época do ano em que são cultivadas, as plantas de crotalária podem atingir até $3,5 \mathrm{~m}$ de altura (Luz et al. 2005), dificultando os tratos culturais e a colheita manual, e impedindo qualquer possibilidade de mecanização. Uma técnica para contornar este problema seria a utilização de reguladores de crescimento capazes de reduzir o porte das plantas.

Os reguladores de crescimento são substâncias químicas sintéticas, que têm efeito sobre o metabolismo vegetal e causam respostas fisiológicas das plantas (Salisbury \& Ross 1994). A maioria deles atua como sinalizador químico, na regulação do crescimento e desenvolvimento de plantas. Normalmente, ligam-se a receptores, na planta, e desencadeiam uma série de mudanças celulares, as quais podem afetar a iniciação ou modificação do desenvolvimento de órgãos ou tecidos. Os reguladores que reduzem a estatura de plantas são normalmente antagonistas às giberelinas e agem modificando o metabolismo destas (Rodrigues et al. 2003).

Os reguladores de crescimento são aplicados com o objetivo de reduzir o desenvolvimento longitudinal indesejável da parte aérea das plantas, sem ocasionar diminuição na produtividade (Rademacher 2000). Porém, os efeitos dos reguladores vegetais têm sido inconsistentes: em algumas situações, verifica-se aumento de produtividade, enquanto, em outras, sua redução (Alvarez et al. 2007). A redução no porte das plantas faz com que os metabólicos sejam direcionados para as estruturas reprodutivas, nas quais estão os produtos de importância econômica (Nóbrega et al. 1999), além de proporcionar maior facilidade nos tratos culturais e na colheita.
Estudos têm mostrado a viabilidade da aplicação de reguladores de crescimento em cevada, soja, arroz, trigo e, principalmente, para a cultura do algodão, visando à redução de porte da planta e uniformidade de maturação (Zagonel et al. 2002, Amabile et al. 2004, Linzmeyer Júnior et al. 2008, Silva 2009). Apesar disto, a sua utilização ainda não é uma prática rotineira, em culturas que não atingiram alto nível tecnológico (Vieira \& Castro 2001). Ainda são escassas as informações sobre os efeitos de reguladores de crescimento sobre a crotalária, tanto na arquitetura das plantas como nos componentes de produção.

Face ao exposto, este trabalho objetivou avaliar a influência da aplicação foliar de reguladores de crescimento, em diferentes doses, sobre o desenvolvimento vegetativo e reprodutivo de Crotalaria juncea cultivada em sistema plantio direto.

\section{MATERIAL E MÉTODOS}

$\mathrm{O}$ experimento foi conduzido entre janeiro e junho de 2010, no município de Selvíria (MS), em área experimental da Fazenda de Ensino, Pesquisa e Extensão da Universidade Estadual Paulista (2020'53'S, 51'24'02'W e $340 \mathrm{~m}$ de altitude). O clima da região, segundo a classificação de Köppen, é do tipo Aw, com precipitação pluvial média anual de $1.330 \mathrm{~mm}$, temperatura média anual de $25^{\circ} \mathrm{C}$ e umidade relativa do ar média anual de $66 \%$ (Centurion 1982). Os dados climáticos registrados, por decêndio, durante o ciclo da cultura, podem ser observados na Figura 1.

O solo da área experimental é classificado como Latossolo Vermelho distrófico álico e de textura argilosa, de acordo com a nova denominação do Sistema Brasileiro de Classificação de Solos (Embrapa 2006), cuja análise química, na camada $0,0-0,20 \mathrm{~m}$, revelou os seguintes valores: $\mathrm{MO}=17 \mathrm{~g} \mathrm{dm}^{-3} ; \mathrm{pH}\left(\mathrm{CaCl}_{2}\right)=5,5 ; \mathrm{P}$ (resina) $=$ $29 \mathrm{mg} \mathrm{dm}{ }^{-3} ; \mathrm{S}=7 \mathrm{mg} \mathrm{dm}{ }^{-3} ; \mathrm{K}=2,7 \mathrm{mmol}_{\mathrm{c}} \mathrm{dm}^{-3}$; $\mathrm{Ca}=31 \mathrm{mmol}_{\mathrm{c}} \mathrm{dm}^{-3} ; \mathrm{Mg}=18 \mathrm{mmol}_{\mathrm{c}} \mathrm{dm}^{-3} ; \mathrm{Al}=$ $1 \mathrm{mmol}_{\mathrm{c}} \mathrm{dm}^{-3} ; \mathrm{H}+\mathrm{Al}=33 \mathrm{mmol}_{\mathrm{c}} \mathrm{dm}^{-3} ; \mathrm{CTC}=$ $85 \mathrm{mmol}_{\mathrm{c}} \mathrm{dm}^{-3}$; e V $=61 \%$.

Não houve preparo do solo, pois trata-se de área cultivada sob sistema plantio direto, implantado há oito anos. Previamente à semeadura, as plantas daninhas presentes na área, na qual predominavam a corda-de-viola [Ipomoea grandifolia (Dammer) O'Donell], a erva-de-santa-luzia [Chamaesyce hirta 


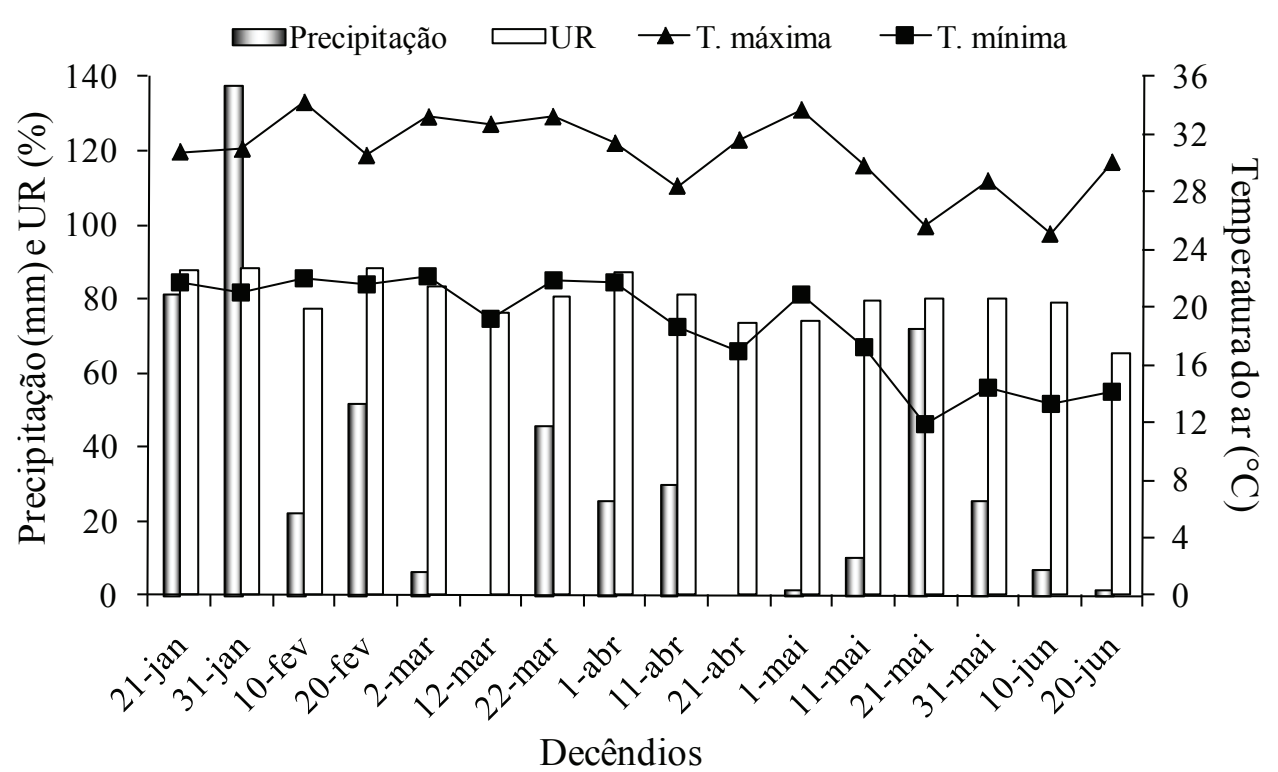

Figura 1. Precipitação pluvial, umidade relativa do ar(UR) e temperatura máxima e mínima do ar, por decêndio, registradas durante a condução do experimento (Selvíria, MS, 2010).

(L.) Millsp], o leiteiro [Euphorbia heterophylla (L.)] e o picão-preto [Bidens pilosa (L.)], foram dessecadas com glyphosate (1.440 $\left.\mathrm{g} \mathrm{ha}^{-1}\right)$. A aplicação do herbicida foi efetuada com pulverizador de barras tratorizado, com vazão de $220 \mathrm{~L} \mathrm{ha}^{-1}$ de calda.

A semeadura da Crotalaria juncea foi realizada mecanicamente, no dia 21 de janeiro de 2010 , distribuindo-se 20 sementes por metro de sulco (30 $\mathrm{kg} \mathrm{ha}^{-1}$ de sementes), à profundidade de $3,0 \mathrm{~cm}$, em espaçamento de $0,34 \mathrm{~m}$ entre as linhas. A emergência das plântulas ocorreu aos cinco dias após a semeadura e a população inicial estabelecida foi de 403.600 plantas ha ${ }^{-1}$.

Foram desenvolvidos quinze tratamentos, resultantes da combinação dos reguladores de crescimento e doses de aplicação, dispostos em delineamento de blocos ao acaso, em esquema fatorial 3x5 (reguladores x doses, respectivamente), com quatro repetições. Por serem produtos de eficiência comprovada e utilizados na redução do porte de diversas culturas, optou-se pela utilização dos reguladores de crescimento cloreto de mepiquat $\left(\right.$ Pix HC ${ }^{\circledR}$ ), etil-trinexapac $\left(\right.$ Moddus $^{\circledR}$ ) e paclobutrazol $\left(\text { Cultar } 250 \mathrm{SC}^{\circledR}\right)^{1}$, aplicados nas seguintes doses: 0 (testemunha, sem aplicação de regulador), $75 \mathrm{~g} \mathrm{ha}^{-1}$, $150 \mathrm{~g} \mathrm{ha}^{-1}, 225 \mathrm{~g} \mathrm{ha}^{-1}$ e $300 \mathrm{~g} \mathrm{ha}^{-1}$ do ingrediente ativo. As aplicações foram realizadas com pulveri-

\footnotetext{
Nomes de produtos comerciais e sua utilização no experimento não caracterizam recomendação ou preferência dos autores.
}

zador costal manual, com capacidade de pressão de trabalho de $6 \mathrm{kgf} \mathrm{cm}^{-2}$, munido de barra com bicos contendo pontas do tipo jato plano ("leque"), modelo 8003 XLR, e volume de calda aproximado de $200 \mathrm{~L} \mathrm{ha}^{-1}$. Os reguladores de crescimento foram aplicados em única vez, aos 30 dias após a emergência das plântulas, momento em que a maioria das plantas apresentava-se com altura entre $80 \mathrm{~cm}$ e $90 \mathrm{~cm}$ e que as condições ambientais eram adequadas à aplicação (umidade relativa do ar de $85 \%$, temperatura média do ar de $27^{\circ} \mathrm{C}$ e velocidade do vento de $8 \mathrm{~km} \mathrm{~h}^{-1}$ ).

As parcelas experimentais foram constituídas por seis linhas de 4,5 $\mathrm{m}$ de comprimento, espaçadas $0,34 \mathrm{~m}$ entre si, perfazendo área total de $9,18 \mathrm{~m}^{2}$ e área útil de $6,12 \mathrm{~m}^{2}$, uma vez que, para a coleta dos dados, foram utilizadas as quatro linhas centrais. A primeira e a sexta linhas foram consideradas bordaduras e, na determinação de produtividade, foram colhidas as duas linhas centrais de cada parcela.

O florescimento pleno da cultura ocorreu aos 62 dias após a emergência. Aos 75 dias após a aplicação dos reguladores de crescimento, foram mensurados, em cinco plantas por parcela, os caracteres altura de planta (região compreendida entre a superfície do solo e a gema do ramo mais alto da planta), diâmetro de caule (considerado a região do caule situada a $0,15 \mathrm{~m}$ da superfície do solo) e número de ramos por planta (contagem das ramificações secundárias do caule). 
A colheita foi realizada no dia 18 de junho de 2010, correspondendo a 143 dias após a emergência, quando a maioria das plantas, nas parcelas, apresentava-se com $95 \%$ das vagens secas. Além da população final de plantas avaliada nesta ocasião, foram mensurados, em dez plantas por parcela, o número de vagens por planta, sementes por vagem (relação entre o número total de sementes oriundas das dez plantas e o número total de vagens) e sementes por planta (relação entre o número total de sementes das dez plantas e o número total de vagens destas). Após a trilha das vagens colhidas na área útil das parcelas, determinou-se a massa média de sementes. Aleatoriamente, foi coletada uma subamostra de 250 sementes por parcela, a qual foi submetida a pesagem, em balança de precisão $(0,01 \mathrm{~g})$, e à determinação do teor de água, possibilitando estimar a massa das sementes, corrigida para $130 \mathrm{~g} \mathrm{~kg}^{-1}$ (base úmida b.u.). Os resultados foram extrapolados para massa de mil sementes. Simultaneamente, determinou-se a produtividade, pela pesagem das sementes oriundas da área útil, a qual foi convertida para $\mathrm{kg} \mathrm{ha}^{-1}$ e corrigida para $130 \mathrm{~g} \mathrm{~kg}^{-1}$ de teor de água (b.u.). O teor de água das sementes foi obtido pelo método elétrico não-destrutivo indireto, mediante o uso do aparelho portátil Multi-grain (Dickey-John ${ }^{\circledR}$ ).

Os resultados foram submetidos a análise de variância (ANOVA), e as médias dos níveis reguladores de crescimento, quando o teste $\mathrm{F}$ foi significativo, comparadas pelo teste Tukey, a 5\%, de acordo com Pimentel Gomes \& Garcia (2002). Por se tratar de fator quantitativo, os efeitos de doses de aplicação foram analisados por regressão polinomial, considerando-se apenas as equações significativas pelo teste $\mathrm{F}(\mathrm{p}<0,05)$. O aplicativo computacional utilizado foi o Sistema de Análise de Variância - Sisvar (Ferreira 2003).

\section{RESULTADOS E DISCUSSÃO}

As aplicações dos reguladores de crescimento influenciaram diretamente no desenvolvimento vegetativo da crotalária (Tabela 1), provocando respostas fisiológicas das plantas, conforme citado por Salisbury \& Ross (1994), dentre elas, a diminuição no alongamento celular. A altura de planta foi influenciada isoladamente pelos reguladores de crescimento e doses de aplicação e pela interação entre estes fatores. Tal resultado deve-se ao fato de os reguladores de crescimento atuarem como sinalizadores químicos na regulação do crescimento e desenvolvimento de plantas. Normalmente, ligam-se a receptores, na planta, e desencadeiam uma série de mudanças celulares, as quais podem afetar a iniciação ou modificação do desenvolvimento de órgãos ou tecidos. Os reguladores que reduzem a estatura de plantas são, normalmente, inibidores da síntese de giberelinas e agem modificando o metabolismo destas (Rodrigues et al. 2003).

Apesar de não terem se diferenciado estatisticamente, a aplicação de etil-trinexapac e paclobutrazol mostraram-se mais eficientes na redução

Tabela 1. Altura de planta (AP), diâmetro de caule (DC), número de ramos por planta (RP) e população final de plantas (PFP) de Crotalaria juncea, em função do uso de reguladores de crescimento, em diferentes doses (Selvíria, MS, 2010).

\begin{tabular}{|c|c|c|c|c|c|}
\hline \multirow{2}{*}{\multicolumn{2}{|c|}{ Tratamentos }} & AP & $\mathrm{DC}$ & RP & PFP \\
\hline & & $\mathrm{cm}$ & $\mathrm{mm}$ & $\mathrm{n}^{\mathrm{o}}$ & plantas ha $^{-1}$ \\
\hline \multicolumn{6}{|c|}{ Regulador - $R$} \\
\hline \multicolumn{2}{|c|}{ Cloreto de mepiquat } & $248,9 \mathrm{a}$ & 8,0 & $4,6 \mathrm{~b}$ & 349.346 \\
\hline \multicolumn{2}{|c|}{ Etil-trinexapac } & $221,9 \mathrm{~b}$ & 7,6 & $4,9 \mathrm{ab}$ & 364.706 \\
\hline \multicolumn{2}{|c|}{ Paclobutrazol } & $217,1 \mathrm{~b}$ & 7,7 & $5,4 \mathrm{a}$ & 347.059 \\
\hline \multicolumn{6}{|c|}{ Dose $\left(g h a^{-1}\right)-D$} \\
\hline \multicolumn{2}{|c|}{0} & 252,2 & 7,9 & 4,6 & 346.950 \\
\hline \multicolumn{2}{|l|}{75} & 228,3 & 7,8 & 4,8 & 343.137 \\
\hline \multicolumn{2}{|l|}{150} & 232,7 & 7,8 & 5,0 & 351.035 \\
\hline \multicolumn{2}{|l|}{225} & 218,2 & 7,5 & 4,9 & 368.464 \\
\hline \multicolumn{2}{|l|}{300} & 215,2 & 7,8 & 5,6 & 358.932 \\
\hline \multicolumn{2}{|c|}{ Média geral } & 229,3 & 7,8 & 5,0 & 353.704 \\
\hline \multicolumn{2}{|l|}{$\mathrm{CV}(\%)$} & 4,68 & 8,12 & 14,30 & 9,79 \\
\hline \multirow{3}{*}{ Valor F } & Regulador & $51,07 * *$ & $2,14^{\mathrm{ns}}$ & $5,65 * *$ & $1,53^{\mathrm{ns}}$ \\
\hline & Dose & $22,30 * *$ & $0,66^{\mathrm{ns}}$ & $3,42 *$ & $1,02^{\mathrm{ns}}$ \\
\hline & $\mathrm{R} \times \mathrm{D}$ & $8,20 * *$ & $2,67 *$ & $1,39^{\mathrm{ns}}$ & $1,34^{\mathrm{ns}}$ \\
\hline
\end{tabular}

**, * e ns: Significativo a $1 \%$ e $5 \%$ e não significativo, respectivamente, pelo teste F. Médias seguidas pela mesma letra, na coluna, não diferem pelo teste Tukey, a $5 \%$. 
da altura de plantas, em comparação ao cloreto de mepiquat, em todas as doses testadas, conforme o desdobramento da interação entre regulador e doses de aplicação (Tabela 2). Tais resultados não deixam qualquer dúvida de que o etil-trinexapac e paclobutrazol reduzem o desenvolvimento vegetativo das plantas, tornando-as mais compactas.

As aplicações de etil-trinexapac e paclobutrazol provocaram redução linear na altura de planta, em resposta ao incremento das doses utilizadas, sendo que a redução observada foi, respectivamente, de $46,0 \mathrm{~cm}$ e $70,8 \mathrm{~cm}$, em comparação ao tratamento testemunha (dose 0$)$ e à maior dose testada $\left(300 \mathrm{~g} \mathrm{ha}^{-1}\right)$ (Figura 2a). Os resultados corroboram o obtido por Linzmeyer Júnior et al. (2008), que, avaliando a influência de doses de etil-trinexapac $\left(0 \mathrm{~L} \mathrm{ha}^{-1}\right.$; $0,2 \mathrm{~L} \mathrm{ha}^{-1} ; 0,4 \mathrm{~L} \mathrm{ha}^{-1} ; 0,6 \mathrm{~L} \mathrm{ha}^{-1} ; 0,8 \mathrm{~L} \mathrm{ha}^{-1} ;$ e 1,0 $\mathrm{L} \mathrm{ha}^{-1}$ ) e duas densidades de semeadura (14 plantas $\mathrm{m}^{-1} \mathrm{e}$ 18 plantas $\mathrm{m}^{-1}$ ), sobre o crescimento, acamamento e produtividade da cultura da soja, no Estado do Paraná, concluíram que a redução na altura das plantas teve relação direta com o aumento da dose utilizada. Os resultados são semelhantes, também, aos obtidos por Alvarez (2003), em Botucatu (SP), que aplicou $200 \mathrm{~g} \mathrm{ha}^{-1}$ de etil-trinexapac, na cultura do arroz, e observou redução de até $34,0 \mathrm{~cm}$, na altura das plantas. Almeida et al. (2000), Zagonel et al. (2002) e Teixeira \& Rodrigues (2003) obtiveram resultados idênticos, sendo que estes últimos observaram redução de 7,7\%, na altura de plantas de cevada.

Por outro lado, as médias de cloreto de mepiquat não tiveram ajustes de equação significativos, demonstrando que este regulador não foi eficiente na redução da estatura das plantas de crotalária, ou seja, na inibição da biossíntese de giberelinas. Fica o indicativo da necessidade de uma aplicação sequencial do regulador cloreto de mepiquat, para que
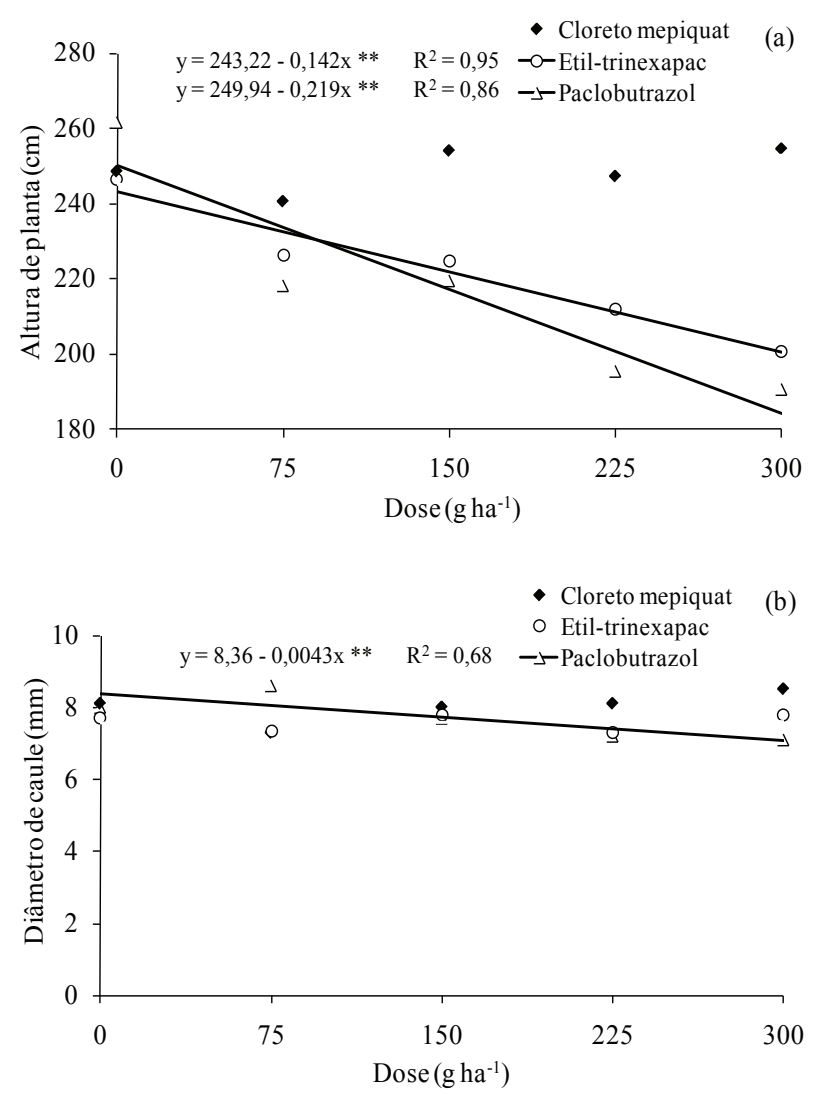

Figura 2. Altura de planta (a) e diâmetro de caule (b) de Crotalaria juncea, em função da aplicação de reguladores de crescimento, em diferentes doses (Selvíria, MS, 2010). ** Significativo a $1 \%$.

haja efeito residual mais prolongado do produto na planta, aumentando a inibição da síntese de giberelina ativa e proporcionando redução mais efetiva da altura das plantas.

Em Selvíria (MS), Buzetti et al. (2006) avaliaram a resposta de cultivares de arroz a doses de nitrogênio e do regulador de crescimento cloreto de

Tabela 2. Altura de planta e diâmetro de caule de Crotalaria juncea, em função do uso de reguladores de crescimento e doses de aplicação (Selvíria, MS, 2010).

\begin{tabular}{|c|c|c|c|c|c|}
\hline \multirow{2}{*}{ Regulador } & \multicolumn{5}{|c|}{ Dose } \\
\hline & $0 \mathrm{~g} \mathrm{ha}^{-1}$ & $75 \mathrm{~g} \mathrm{ha}^{-1}$ & $150 \mathrm{~g} \mathrm{ha}^{-1}$ & $225 \mathrm{~g} \mathrm{ha}^{-1}$ & $300 \mathrm{~g} \mathrm{ha}^{-1}$ \\
\hline \multirow{4}{*}{$\begin{array}{l}\text { Cloreto de mepiquat } \\
\text { Etil-trinexapac } \\
\text { Paclobutrazol }\end{array}$} & \multicolumn{5}{|c|}{ Altura de planta $(\mathrm{cm})$} \\
\hline & $248,5 \mathrm{a}$ & $240,5 \mathrm{a}$ & $254,0 \mathrm{a}$ & $247,2 \mathrm{a}$ & $254,5 \mathrm{a}$ \\
\hline & $246,5 \mathrm{a}$ & $226,2 \mathrm{ab}$ & 224,7 b & $211,7 \mathrm{~b}$ & $200,5 \mathrm{~b}$ \\
\hline & $261,5 \mathrm{a}$ & $218,2 \mathrm{~b}$ & $219,5 \mathrm{~b}$ & $195,5 \mathrm{~b}$ & $190,7 \mathrm{~b}$ \\
\hline \multirow{4}{*}{$\begin{array}{l}\text { Cloreto de mepiquat } \\
\text { Etil-trinexapac } \\
\text { Paclobutrazol }\end{array}$} & \multicolumn{5}{|c|}{ Diâmetro de caule $(\mathrm{mm})$} \\
\hline & $8,1 \mathrm{a}$ & $7,3 \mathrm{~b}$ & $8,0 \mathrm{a}$ & $8,1 \mathrm{a}$ & $8,5 \mathrm{a}$ \\
\hline & $7,7 \mathrm{a}$ & $7,4 \mathrm{~b}$ & $7,8 \mathrm{a}$ & $7,3 \mathrm{a}$ & $7,8 \mathrm{ab}$ \\
\hline & $8,0 \mathrm{a}$ & $8,6 \mathrm{a}$ & $7,7 \mathrm{a}$ & $7,2 \mathrm{a}$ & $7,1 \mathrm{~b}$ \\
\hline
\end{tabular}

Médias seguidas pela mesma letra, na coluna, não diferem pelo teste Tukey, a $5 \%$. 
clormequat, que possui modo de ação semelhante ao cloreto de mepiquat, e verificaram que o regulador não influenciou na altura das cultivares de arroz de terras altas IAC 201 e IAC 202. No entanto, o efeito do cloreto de mepiquat foi avaliado na cultura do algodão, por Lamas et al. (2000), os quais observaram redução na altura de planta, com o aumento das doses aplicadas $\left(0 \mathrm{~g} \mathrm{ha}^{-1}, 50 \mathrm{~g} \mathrm{ha}^{-1}, 75 \mathrm{~g} \mathrm{ha}^{-1}, 100 \mathrm{~g} \mathrm{ha}^{-1} \mathrm{e}\right.$ $\left.150 \mathrm{~g} \mathrm{ha}^{-1}\right)$.

O diâmetro de caule foi afetado somente pela interação entre reguladores de crescimento e doses de aplicação (Tabela 1). Na análise do desdobramento, não se constatou diferença entre os reguladores de crescimento, no tratamento testemunha e nas doses de $150 \mathrm{~g} \mathrm{ha}^{-1}$ e $225 \mathrm{~g} \mathrm{ha}^{-1}$ (Tabela 2). Nas demais doses, houve comportamento distinto entre os reguladores, observando-se que a aplicação de etil-trinexapac proporcionou menor diâmetro de caule, em ambas as doses, contudo, não se diferenciou do cloreto de mepiquat, na dose de $75 \mathrm{~g} \mathrm{ha}^{-1}$, e do paclobutrazol, na dose de $300 \mathrm{~g} \mathrm{ha}^{-1}$.

A aplicação de paclobutrazol proporcionou redução linear no diâmetro de caule, à medida que se aumentou a dose do produto (Figura 2b), e isto não é interessante para a cultura, em campos de produção de sementes, pois esta característica morfológica está diretamente relacionada ao percentual de acamamento das plantas. O mesmo efeito não foi observado com os demais reguladores de crescimento, ratificando o resultado obtido por Zagonel et al. (2002), na cultura do trigo, os quais não verificaram alterações no diâmetro de caule de planta, quando este recebeu a aplicação de $125 \mathrm{~g} \mathrm{ha}^{-1}$ de etil-trinexapac. Por outro lado, Linzmeyer Júnior et al. (2008) constataram resposta polinomial quadrática do diâmetro de caule ao aumento da dose de etil-trinexapac aplicada à cultura da soja. Os referidos autores atribuíram tal resultado ao fato de que o etil-trinexapac inibe a síntese de giberelina e, assim, as plantas sintetizam giberelinas menos eficientes, reduzindo o alongamento celular e o engrossamento de entrenós, sem causar deformação morfológica do caule, conforme destacado por Taiz \& Zeiger (1998).

No tocante ao número de ramos por planta, houve apenas efeito isolado de reguladores de crescimento e doses de aplicação (Tabela 1). A aplicação de paclobutrazol proporcionou a obtenção de plantas com maior número de ramificações, apesar de não ter sido constatada superioridade estatística, em relação ao etil-trinexapac. Isto pode ser explicado pela perda da dominância apical das plantas, proporcionada pela ação dos reguladores de crescimento, ocorrendo, consequentemente, estímulo das gemas vegetativas localizadas nas laterais do caule, que, até então, se apresentavam dormentes, refletindo em maior número de ramos por planta. No tocante à análise de regressão para o efeito de doses, observa-se que, à medida que foram aumentadas, houve incremento linear no número de ramos por planta (Figura 3), sendo a dose de $300 \mathrm{~g} \mathrm{ha}^{-1}$ a que promoveu maiores ramificações. Fica claramente evidenciado que, nos tratamentos que não receberam a aplicação de quaisquer reguladores, ocorreu maior dominância da gema apical das plantas, pois, nas testemunhas, a biossíntese de giberelinas não é inibida e, portanto, o número de ramos por planta é menor. Contudo, é oportuno ressaltar que, apesar de ter ocorrido ajuste significativo, pela equação de regressão $(p<0,01)$, a diferença entre o tratamento testemunha e a maior dose testada (300 $\left.\mathrm{g} \mathrm{ha}^{-1}\right)$ foi, em média, de apenas um ramo por planta.

A população final de plantas não foi afetada pelos reguladores de crescimento (Tabela 1), haja vista que, por ocasião das aplicações, as plantas estavam com um porte vegetativo considerável (entre $80 \mathrm{~cm}$ e $90 \mathrm{~cm}$ de altura). Esta é uma importante informação e, deste modo, pode-se afirmar que a população de plantas não afetou os resultados das demais avaliações realizadas neste estudo. Os reguladores de crescimento influenciaram no desenvolvimento da maioria dos caracteres produtivos da crotalária. $\mathrm{O}$ número de vagens e sementes por planta apresentaram comportamento semelhante, sendo influenciados isoladamente pelos reguladores de crescimento e

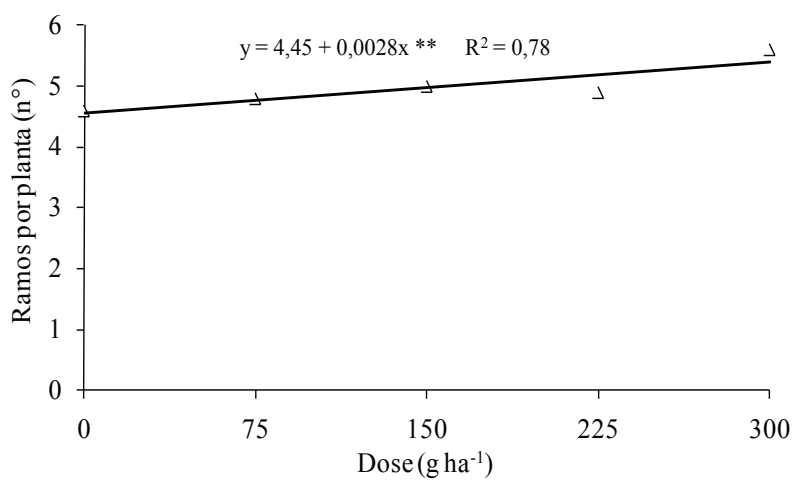

Figura 3. Número de ramos por planta de Crotalaria juncea, em função da aplicação de reguladores de crescimento, em diferentes doses (Selvíria, MS, 2010). ** Significativo a $1 \%$. 
Tabela 3. Número de vagens por planta (VP), sementes por vagem (SV), sementes por planta (SP), massa de mil sementes (MMS) e produtividade (PROD) de Crotalaria juncea, em função do uso de reguladores de crescimento, em diferentes doses (Selvíria, MS, 2010).

\begin{tabular}{|c|c|c|c|c|c|c|}
\hline \multirow{2}{*}{\multicolumn{2}{|c|}{ Tratamentos }} & VP & SV & SP & $\mathrm{MMS}^{(1)}$ & $\mathrm{PROD}^{(1)}$ \\
\hline & & & $-\mathrm{n}^{\mathrm{o}}$ & & $\mathrm{g}$ & $\mathrm{kg} \mathrm{ha}^{-1}$ \\
\hline \multicolumn{7}{|c|}{ Regulador - $R$} \\
\hline \multicolumn{2}{|c|}{ Cloreto de mepiquat } & $4,6 \mathrm{~b}$ & 3,9 & $18,3 \mathrm{~b}$ & 45,4 & $199,8 \quad b$ \\
\hline \multicolumn{2}{|c|}{ Etil-trinexapac } & $5,9 \mathrm{a}$ & 3,5 & $20,9 \mathrm{ab}$ & 46,4 & $251,0 \mathrm{a}$ \\
\hline \multicolumn{2}{|c|}{ Paclobutrazol } & $6,5 \mathrm{a}$ & 3,6 & $23,1 \mathrm{a}$ & 46,5 & $213,8 \quad b$ \\
\hline \multicolumn{7}{|c|}{ Dose $\left(g h a^{-1}\right)-D$} \\
\hline \multicolumn{2}{|l|}{0} & 4,7 & 3,5 & 16,8 & 46,2 & 290,7 \\
\hline \multicolumn{2}{|l|}{75} & 4,9 & 3,6 & 17,4 & 45,7 & 239,7 \\
\hline \multicolumn{2}{|l|}{150} & 5,7 & 3,4 & 19,6 & 46,5 & 192,0 \\
\hline \multicolumn{2}{|l|}{225} & 6,8 & 3,9 & 26,4 & 46,4 & 200,0 \\
\hline \multicolumn{2}{|l|}{300} & 6,2 & 3,8 & 23,6 & 45,5 & 185,2 \\
\hline \multicolumn{2}{|c|}{ Média geral } & 5,7 & 3,7 & 20,8 & 46,1 & 221,5 \\
\hline \multicolumn{2}{|c|}{$\mathrm{CV}(\%)$} & 18,96 & 16,79 & 24,29 & 4,21 & 20,96 \\
\hline \multirow{3}{*}{ Valor F } & Regulador & $15,32 * *$ & $1,76^{\mathrm{ns}}$ & $4,50 *$ & $1,94^{\mathrm{ns}}$ & $6,49 * *$ \\
\hline & Dose & $8,06 * *$ & $1,30^{\mathrm{ns}}$ & $8,08 * *$ & $0,59^{\text {ns }}$ & $10,82 * *$ \\
\hline & $R \times D$ & $4,02 * *$ & $1,13^{\mathrm{ns}}$ & $3,19 * *$ & $0,68^{\mathrm{ns}}$ & $5,87 * *$ \\
\hline
\end{tabular}

**, * e ns: Significativo a $1 \%$ e $5 \%$ e não significativo, pelo teste $\mathrm{F}$, respectivamente. Médias seguidas pela mesma letra, na coluna, não diferem pelo teste Tukey, a $5 \%$. (1) Com base em $130 \mathrm{~g} \mathrm{~kg}^{-1}$ de teor de água nas sementes.

doses de aplicação e pela interação entre estes fatores (Tabela 3).

Semelhantemente ao verificado para o número de ramos por planta, a aplicação de etil-trinexapac e paclobutrazol proporcionou a obtenção de maior número de vagens e sementes por planta, em relação ao cloreto de mepiquat. No entanto, esta semelhança se manteve apenas no tratamento testemunha e nas doses de $75 \mathrm{~g} \mathrm{ha}^{-1}$ e $225 \mathrm{~g} \mathrm{ha}^{-1}$ (Tabela 4). Na aplicação de $150 \mathrm{~g} \mathrm{ha}^{-1}$, o paclobutrazol monstrou-se vantajoso, por refletir em maior número de vagens por planta, enquanto, para o número de sementes por planta, não houve diferença entre os reguladores, nesta dose. $\mathrm{Na}$ maior dose testada (300 $\left.\mathrm{g} \mathrm{ha}^{-1}\right)$, o efeito sobre o número de vagens e de sementes por planta foi similar, evidenciando-se maiores valores, quando aplicados cloreto de mepiquat e paclobutrazol.
A elevação das doses de aplicação de cloreto de mepiquat e paclobutrazol ocasionou aumento linear, tanto no número de vagens por planta quanto no número de sementes por planta (Figuras 4a e 4b), ratificando Hertwig (1992), ao mencionar que plantas que receberam aplicações de reguladores de crescimento, os quais inibem a síntese de giberelina, podem apresentar, como resultado, aumento no número de vagens. Apesar de ficar evidente a importante participação dos reguladores no incremento de ambos os caracteres produtivos, os números foram considerados baixos, em todas as doses. Porém, nota-se que, nos tratamentos que não receberam aplicação de cloreto de mepiquat e paclobutrazol, o número de vagens e sementes por planta foram, em média, ainda menores.

Os resultados do presente estudo discordam dos obtidos por Campos (2005), que, trabalhando

Tabela 4. Número de vagens e de sementes por planta de Crotalaria juncea, em função do uso de reguladores de crescimento e doses de aplicação (Selvíria, MS, 2010).

\begin{tabular}{lccccc}
\hline \multirow{2}{*}{ Regulador } & \multicolumn{5}{c}{ Dose } \\
\cline { 2 - 6 } & $0 \mathrm{~g} \mathrm{ha}^{-1}$ & $75 \mathrm{~g} \mathrm{ha}^{-1}$ & $150 \mathrm{~g} \mathrm{ha}^{-1}$ & $225 \mathrm{~g} \mathrm{ha}^{-1}$ & $300 \mathrm{~g} \mathrm{ha}^{-1}$ \\
\cline { 2 - 6 } Cloreto de mepiquat & \multicolumn{7}{c}{ Número de vagens por planta $^{2}$} \\
Etil-trinexapac & $5,3 \mathrm{~b}$ & $3,8 \mathrm{~b}$ & $5,1 \mathrm{~b}$ & $4,6 \mathrm{~b}$ & $6,4 \mathrm{ab}$ \\
Paclobutrazol & $5,1 \mathrm{a}$ & $5,0 \mathrm{~b}$ & $7,9 \mathrm{a}$ & $5,1 \mathrm{~b}$ \\
\hline & $5,6 \mathrm{a}$ & $4,7 \mathrm{ab}$ & $7,1 \mathrm{a}$ & $8,0 \mathrm{a}$ & $7,0 \mathrm{a}$ \\
Cloreto de mepiquat & $11,2 \mathrm{~b}$ & $13,0 \mathrm{~b}$ & $19,0 \mathrm{a}$ & $20,0 \mathrm{~b}$ & $28,3 \mathrm{a}$ \\
Etil-trinexapac & $18,9 \mathrm{ab}$ & $21,9 \mathrm{a}$ & $16,7 \mathrm{a}$ & $28,0 \mathrm{ab}$ & $19,1 \mathrm{~b}$ \\
Paclobutrazol & $20,3 \mathrm{a}$ & $17,3 \mathrm{ab}$ & $22,9 \mathrm{a}$ & $31,3 \mathrm{a}$ & $23,4 \mathrm{ab}$ \\
\hline
\end{tabular}

Médias seguidas pela mesma letra, na coluna, não diferem pelo teste Tukey, a 5\%. 

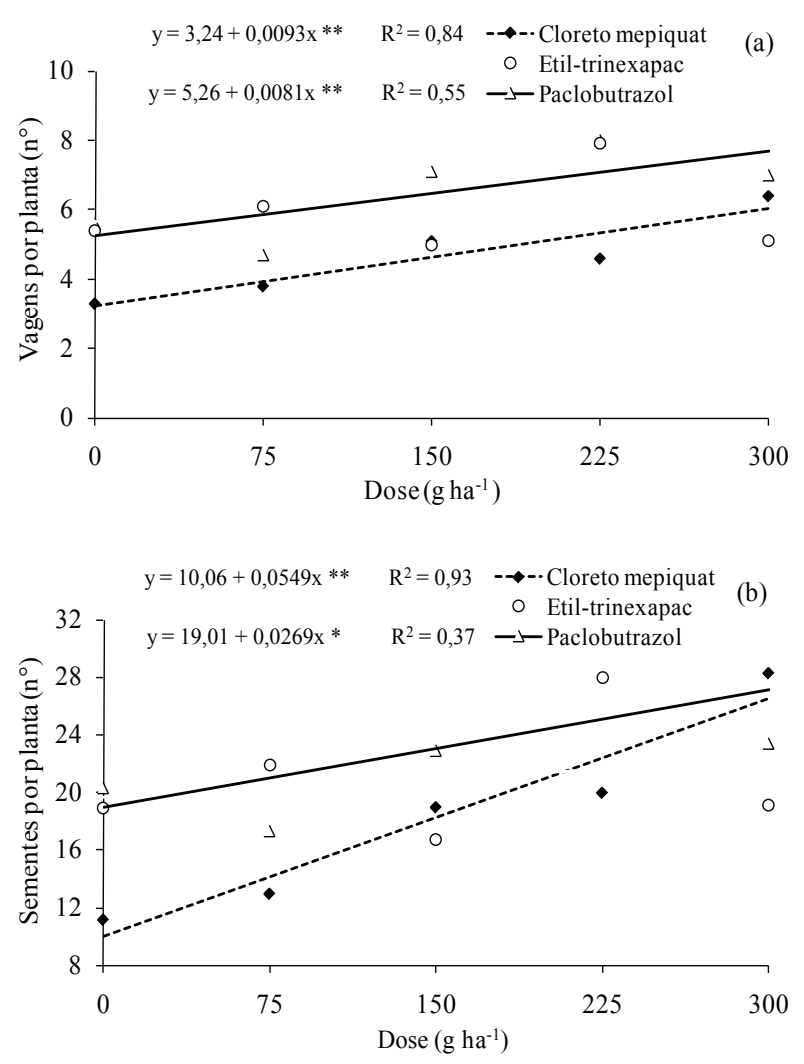

Figura 4. Número de vagens por planta (a) e de sementes por planta (b) de Crotalaria juncea, em função da aplicação de reguladores de crescimento, em diferentes doses (Selvíria, MS, 2010). ${ }^{* *}$ e * Significativo a $1 \%$ e $5 \%$, respectivamente.

com diversos reguladores de crescimento, na cultura da soja, dentre eles o cloreto de mepiquat, relatou que o número de vagens por planta não foi influenciado pelos reguladores aplicados. Os resultados obtidos com a dose de $300 \mathrm{~g} \mathrm{ha}^{-1}$ (Tabela 4) justificam, para ambos os caracteres, a ausência de ajuste de equação linear significativa para o etil-trinexapac, em função do aumento nas doses de aplicação. A ausência de efeito de doses de etil-trinexapac sobre o número de vagens por planta também foi verificada por Linzmeyer Júnior et al. (2008), na soja.

Os reguladores de crescimento proporcionam redução no porte das plantas, fazendo com que os metabólicos sejam direcionados para as estruturas reprodutivas das mesmas (Nóbrega et al. 1999), entretanto, este último efeito, provavelmente, não tenha ocorrido no presente estudo, pois o número de sementes por vagem e a massa de mil sementes, importantes componentes de produção, tiveram comportamento similar e não foram influenciados pela aplicação destas substâncias (Tabela 3). Estes resultados corroboram os observados por Campos (2005) e Linzmeyer Júnior et al. (2008), os quais relataram que o número de sementes por vagem e massa de cem sementes de soja não foram afetados pela aplicação dos reguladores de crescimento testados. Por outro lado, em condições semelhantes de estudo, Nascimento et al. (2009) testaram a aplicação de cinco doses do regulador de crescimento etil-trinexapac $\left(0 \mathrm{~g} \mathrm{ha}^{-1}, 75 \mathrm{~g} \mathrm{ha}^{-1}, 150 \mathrm{~g} \mathrm{ha}^{-1}, 225 \mathrm{~g} \mathrm{ha}^{-1}\right.$ e $\left.300 \mathrm{~g} \mathrm{ha}^{-1}\right)$, em arroz de terras altas, e constataram ajuste de equação quadrática para a massa de cem sementes.

$\mathrm{O}$ fato evidenciado no presente estudo leva à conclusão de que o número de sementes por vagem e massa média de sementes não são caracteres influenciados por práticas de manejo fitotécnico, mas sim determinados pelo próprio genótipo. Na cultura do milho, Sangoi et al. (2002) relataram que a massa de sementes é o componente produtivo menos afetado por variações nas práticas de manejo. Todavia, é oportuno destacar que o número de sementes por vagem e a massa de sementes da crotalária, em determinadas épocas e condições climáticas, podem ser influenciados negativamente, especialmente durante a fase reprodutiva da cultura, sob déficit hídrico e temperaturas elevadas.

No tocante à produtividade, houve influência isolada de reguladores de crescimento e doses de aplicação e da interação entre estes fatores (Tabela 3). Quando aplicados nas doses de $150 \mathrm{~g} \mathrm{ha}^{-1}$ e $225 \mathrm{~g} \mathrm{ha}^{-1}$, os reguladores cloreto de mepiquat e etil-trinexapac apresentaram o mesmo comportamento, proporcionando maior produtividade, em comparação à aplicação de paclobutrazol, nestas doses (Tabela 5). No tratamento testemunha e na dose de $300 \mathrm{~g} \mathrm{ha}^{-1}$, a aplicação de etil-trinexapac e paclobutrazol favoreceram a obtenção de maior produtividade. Na dose de $75 \mathrm{~g} \mathrm{ha}^{-1}$, a aplicação de paclobutrazol se manteve vantajosa, por proporcionar maior produtividade, apesar de não ter se diferenciado do cloreto de mepiquat, nesta dose.

Assim como para a maioria das culturas, a produtividade da crotalária é determinada pelo número de vagens e sementes por área e pela massa das sementes. No entanto, neste estudo, apesar de o número de vagens e sementes por planta terem aumentado linearmente, em função do incremento nas doses de cloreto de mepiquat e paclobutrazol, a mesma tendência não foi notada para a produti- 
Tabela 5. Produtividade de Crotalaria juncea, em função do uso de reguladores de crescimento e doses de aplicação (Selvíria, MS, 2010).

\begin{tabular}{llllll}
\hline \multirow{2}{*}{ Regulador } & \multicolumn{5}{c}{ Dose } \\
\cline { 2 - 6 } & $0 \mathrm{~g} \mathrm{ha}^{-1}$ & $75 \mathrm{~g} \mathrm{ha}^{-1}$ & $150 \mathrm{~g} \mathrm{ha}^{-1}$ & $225 \mathrm{~g} \mathrm{ha}^{-1}$ & $300 \mathrm{~g} \mathrm{ha}^{-1}$ \\
\cline { 2 - 6 } Cloreto de mepiquat & $249,7 \mathrm{~b}$ & $227,1 \mathrm{ab}$ & $202,8 \mathrm{a}$ & $193,5 \mathrm{ab}$ & $125,9 \mathrm{~b}$ \\
Etil-trinexapac & $287,5 \mathrm{ab}$ & $201,8 \mathrm{~b}$ & $256,2 \mathrm{a}$ & $264,5 \mathrm{a}$ & $244,8 \mathrm{a}$ \\
Paclobutrazol & $335,0 \mathrm{a}$ & $290,2 \mathrm{a}$ & $116,9 \mathrm{~b}$ & $141,9 \mathrm{~b}$ & $185,0 \mathrm{ab}$ \\
\hline
\end{tabular}

Médias seguidas pela mesma letra, na coluna, não diferem pelo teste Tukey, a $5 \%$.

vidade. O aumento nas doses destes reguladores de crescimento reduziu linearmente a produtividade da crotalária (Figura 5).

Outros trabalhos também evidenciaram reduções de produtividade, com a aplicação de reguladores de crescimento em culturas importantes. Silva (2009) conduziu dois experimentos, um em Fernandópolis (SP) e outro em Selvíria (MS), com o objetivo de estudar o efeito de etil-trinexapac em diferentes densidades de semeadura do arroz de terras altas, e, ao término da pesquisa, concluiu que a aplicação deste produto reduziu a produtividade da cultura, nas duas localidades. Alvarez et al. (2007) verificaram que, apesar de o regulador etil-trinexapac ter reduzido a altura de planta, este influenciou negativamente os componentes de produção e a produtividade do arroz. Contrariamente aos resultados obtidos por estes autores, Zagonel et al. (2002) verificaram aumento na produtividade do trigo, após a aplicação de $125 \mathrm{~g} \mathrm{ha}^{-1}$ de etil-trinexapac. De modo similar, Nascimento et al. (2009) obtiveram incremento linear e quadrático na produtividade de arroz, em função da aplicação de doses de etil-trinexapac, entre as fases de perfilhamento ativo e

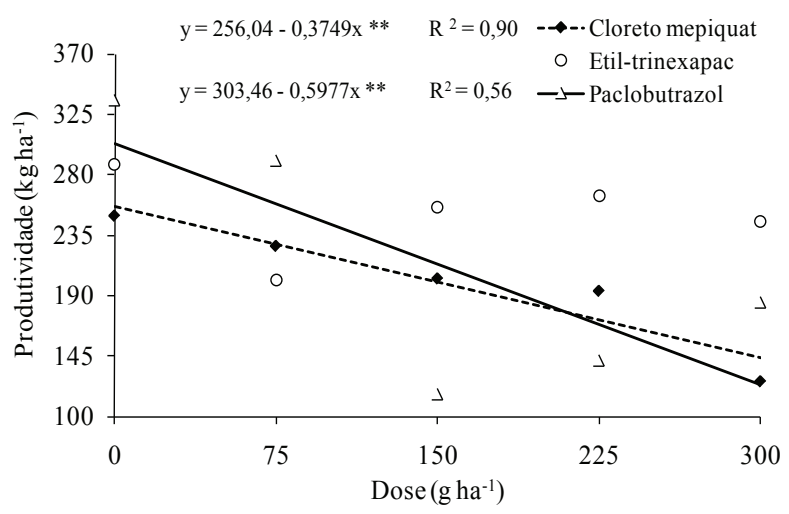

Figura 5. Produtividade de Crotalaria juncea, em função da aplicação de reguladores de crescimento, em diferentes doses (Selvíria, MS, 2010). ** Significativo a 1\%. diferenciação floral e na fase de diferenciação floral, respectivamente.

As variações nas doses do regulador etil-trinexapac não interferiram na produtividade das plantas de crotalária tratadas. Provavelmente, isto se deva ao baixo efeito residual do produto, não estando este presente no estádio reprodutivo das plantas, pois foi realizada apenas uma aplicação do regulador no estádio fenológico vegetativo da cultura. A não influência deste regulador de crescimento sobre a produtividade observada no presente estudo corrobora, em parte, os resultados obtidos por Amabile et al. (2004) e Linzmeyer Júnior et al. (2008), ao efetuarem aplicações do mesmo produto na cultura da cevada e da soja, respectivamente.

Desta maneira, evidencia-se, novamente, o contraste e a inconsistência dos resultados de aplicações de reguladores de crescimento, conforme ressaltaram Alvarez et al. (2007), para a produtividade. Ao mesmo tempo, mostra-se a necessidade da realização de mais estudos sobre a utilização destas substâncias sintéticas, em diferentes culturas, principalmente quando se tratam de diferentes reguladores de crescimento, doses e épocas de aplicação.

A aplicação de reguladores de crescimento constitui ferramenta importante no manejo fitotécnico da Crotalaria juncea, quando se tratam de campos de produção de sementes, por diminuir a estatura das plantas e facilitar a colheita, mas que, ainda, influencia, negativamente, um produto de importância econômica, no caso, as sementes.

É oportuno ressaltar que a produtividade obtida neste estudo foi considerada baixa e isto pode ser atribuído a, pelo menos, dois fatores: incidência de oídio (Erysiphe polygoni DC), na fase reprodutiva da cultura, e ataque da lagarta-das-vagens-da-crotalária [Utetheisa ornatrix (L.)] (Lepidoptera: Arctiidae), comumente encontrada nas lavouras, que, em função da época do ataque e do porte das plantas, nesta ocasião, dificultou a aplicação de produtos específicos ao seu controle. 


\section{CONCLUSÕES}

1. Os reguladores de crescimento influenciaram o desenvolvimento vegetativo e reprodutivo da Crotalaria juncea, sendo que o incremento nas doses de etil-trinexapac e paclobutrazol reduziu a altura de plantas, enquanto o cloreto de mepiquat e paclobutrazol aumentaram o número de vagens e sementes por planta.

2. A população final de plantas, número de sementes por vagem e massa de mil sementes não foram influenciados pela aplicação foliar dos reguladores de crescimento.

3. O aumento nas doses de aplicação dos reguladores proporcionou incremento linear no número de ramos por planta, ao passo que as doses de cloreto de mepiquat e paclobutrazol reduziram a produtividade, portanto, não se recomenda a aplicação de tais produtos na cultura da crotalária, visando à produção de sementes.

\section{AGRADECIMENTOS}

À Universidade Estadual Paulista (Unesp), Campus de Ilha Solteira, pelos recursos humanos e materiais, e à Fundação de Amparo à Pesquisa do Estado de São Paulo (FAPESP), pela bolsa de estudo concedida ao primeiro autor.

\section{REFERÊNCIAS}

ALMEIDA, J. L.; RUPPEL, E. C.; KUNZ, R. Efeito da aplicação do regulador de crescimento trinexapac-etil na cultura da cevada. In: REUNIÃO ANUAL DE PESQUISA DE CEVADA, 20., 2000, Passo Fundo. Anais... Passo Fundo: Embrapa Trigo, 2000. p. 55-58.

ALVAREZ, R. C. F. Absorção, distribuição e redistribuição de nitrogênio $\left({ }^{15} \mathrm{~N}\right)$ em cultivares de arroz de terras altas em função da aplicação de reguladores vegetais. 2003. $87 \mathrm{f}$. Tese (Doutorado em Agronomia)-Faculdade de Ciências Agronômicas, Universidade Estadual Paulista, Botucatu, 2003.

ALVAREZ, R. C. F. et al. Influência do etil-trinexapac no acúmulo, na distribuição de nitrogênio $\left({ }^{15} \mathrm{~N}\right)$ e na massa de grãos de arroz de terras altas. Revista Brasileira de Ciência do Solo, Viçosa, v. 31, n. 6, p. 1487-1496, 2007.

AMABILE, R. F. et al. Efeito do regulador de crescimento trinexapac-etil em cevada cervejeira irrigada em áreas de Cerrado no Distrito Federal. Planaltina: Embrapa Cerrados, 2004. (Boletim de pesquisa e desenvolvimento, 120).
BUZETTI, S. et al. Resposta de cultivares de arroz a doses de nitrogênio e do regulador de crescimento cloreto de clormequat. Pesquisa Agropecuária Brasileira, Brasília, DF, v. 41, n. 12, p. 1731-1737, 2006.

CAMPOS, M. F. Efeitos de reguladores vegetais no desenvolvimento de plantas de soja (Glycine max (L.) Merrill). 2005. 131 f. Tese (Doutorado em Ciências Biológicas)-Faculdade de Ciências Agronômicas, Universidade Estadual Paulista, Botucatu, 2005.

CENTURION, J. F. Balanço hídrico da região de Ilha Solteira. Cientifica, Jaboticabal, v. 10, n. 1, p. 57-61, 1982.

DOURADO, M. C.; SILVA, T. R. B.; BOLONHEZI, A. C. Matéria seca e produção de grãos de Crotalaria juncea $\mathrm{L}$. submetida à poda e adubação fosfatada. Scientia Agricola, Piracicaba, v. 58, n. 2, p. 287-293, 2001.

EMPRESA BRASILEIRA DE PESQUISA AGROPECUÁRIA (Embrapa). Centro Nacional de Pesquisa de Solos. Sistema brasileiro de classificação de solos. 2. ed. Brasília, DF: Embrapa-SPI; Rio de Janeiro: Embrapa Solos, 2006.

ERASMO, E. A. L. et al. Potencial de espécies utilizadas como adubo verde no manejo integrado de plantas daninhas. Planta Daninha, Viçosa, MG, v. 22, n. 3, p. $337-$ 342, 2004.

FAVERO, C. et al. Modificação na população de plantas espontâneas na presença de adubos verdes. Pesquisa Agropecuária Brasileira, Brasília, DF, v. 36, n. 11, p. 13551362, 2001.

FERREIRA, D. F. Sisvar: sistema de análise de variância para dados balanceados. Versão 5.0. Lavras: UFLa, 2003.

GUERRA, J. G. M.; DE-POLLI, H.; ALMEIDA, D. L. Managing carbon and nitrogen in tropical organic farming trough green manuring. In: ADETOLA BADEJO, M.; TOGUN, A. O. (Eds.). Strategies and tactics of sustainable agriculture in the tropics. Ibadan: College Press, 2004. p. $125-140$.

HERTWIG, K. V. Manual de herbicidas desfolhantes, dessecantes e fitorreguladores. São Paulo: Agronômica Ceres, 1992.

KAPPES, C. Utilizações e benefícios da crotalária na agricultura. Revista Panorama Rural, Ribeirão Preto, n. 147, p. 16-17, 2011.

LAMAS, F. M.; ATHAYDE, M. L. F.; BANZATTO, D. A. Reações do algodoeiro CNPA-ITA 90 ao cloreto de mepiquat. Pesquisa Agropecuária Brasileira, Brasília, DF, v. 35, n. 3, p. 507-516, 2000.

LINZMEYER JÚNIOR, R. et al. Influência de retardante vegetal e densidades de plantas sobre o crescimento, acamamento e produtividade da soja. Acta Scientiarum Agronomy, Maringá, v. 30, n. 3, p. 373-379, 2008. 
LUZ, P. H. C. et al. Utilização de adubação verde na cultura da cana-de-açúcar. Piracicaba: ESALQ/USP, 2005.

MALAVOLTA, E.; GOMES, F. P.; ALCARDE, J. C. Adubos e adubações. São Paulo: Nobel, 2000.

NASCIMENTO, V. et al. Uso do regulador de crescimento etil-trinexapac em arroz de terras altas. Bragantia, Campinas, v. 68, n. 4, p. 921-929, 2009.

NÓBREGA, L. B. et al. Hormônios e reguladores do crescimento e do desenvolvimento. In: BELTRÃO, N. E. M. (Ed.). O agronegócio do algodão no Brasil. Brasília, DF: Embrapa Comunicação para Transferência de Tecnologia, 1999. p. 587-602.

PEREIRA, A. J. et al. Desempenho agronômico de Crotalaria juncea em diferentes arranjos populacionais e épocas do ano. Seropédica: Embrapa Agrobiologia, 2005. (Comunicado técnico, 82).

PIMENTEL GOMES, F.; GARCIA, C. H. Estatística aplicada a experimentos agronômicos e florestais: exposição com exemplos e orientações para uso de aplicativos. Piracicaba: Fealq, 2002.

RADEMACHER, W. Growth retardants: effects on gibberellin biosynthesis and other metabolic pathways. Annual Review of Plant Physiology and Plant Molecular Biology, Palo Alto, v. 51, n. 1, p. 501-531, 2000.

RODRIGUES, O. et al. Redutores de crescimento. Passo Fundo: Embrapa Trigo, 2003. (Circular técnica, 14).
SALISBURY, F. B.; ROSS, C. W. Fisiologia vegetal. Cidade do México: Iberoamérica, 1994.

SANGOI, L. et al. Response of Brazilian maize hybrids from different eras to changes in plant density. Field Crops Research, Amsterdam, v. 79, n. 1, p. 39-51, 2002.

SILVA, M. R. R. Regulador de crescimento etil-trinexapac em diferentes densidades de semeadura na cultura do arroz de terras altas. 2009. 81 f. Tese (Doutorado em Agronomia)-Faculdade de Engenharia, Universidade Estadual Paulista, Ilha Solteira, 2009.

TAIZ, L.; ZEIGER, E. Plant physiology. 2. ed. Sunderland: Sinauer Associates, 1998.

TEIXEIRA, M. C. C.; RODRIGUES, O. Efeito da adubação nitrogenada, arranjo de plantas e redutor de crescimento no acamamento e em características de cevada. Passo Fundo: Embrapa Trigo, 2003. (Boletim de pesquisa e desenvolvimento, 20).

VIEIRA, E. L.; CASTRO, P. R. C. Ação de bioestimulante na germinação de sementes, vigor das plântulas, crescimento radicular e produtividade de soja. Revista Brasileira de Sementes, Brasília, DF, v. 23, n. 2, p. 222228, 2001.

ZAGONEL, J. et al. Doses de nitrogênio e densidades de plantas com e sem um regulador de crescimento afetando o trigo, cultivar OR-1. Ciência Rural, Santa Maria, v. 32, n. 1, p. 25-29, 2002. 